\title{
Vitamin D status among immigrant mothers from Pakistan, Turkey and Somalia and their infants attending child health clinics in Norway
}

\author{
Ahmed A. Madar ${ }^{1}$, Lars C. Stene ${ }^{2}$ and Haakon E. Meyer ${ }^{1,2}$ \\ ${ }^{1}$ Institute of General Practice and Community Medicine, University of Oslo, PO Box 1130, Blindern, N-0318 Oslo, Norway \\ ${ }^{2}$ Division of Epidemiology, Norwegian Institute of Public Health, Oslo, Norway
}

(Received 8 January 2008 - Revised 14 July 2008 - Accepted 14 July 2008 - First published online 9 September 2008)

High prevalences of vitamin D deficiency have been reported in non-Western immigrants moving to Western countries, including Norway, but there is limited information on vitamin D status in infants born to immigrant mothers. We aimed to describe the vitamin D status and potentially correlated factors among infants aged 6 weeks and their mothers with Pakistani, Turkish or Somali background attending child health clinics in Norway. Eighty-six healthy infants and their mothers with immigrant background were recruited at the routine 6-week check-up at nine centres between 2004 and 2006. Venous or capillary blood was collected at the clinics from the mother and infant, and serum separated for analysis of 25-hydroxyvitamin D (s-25(OH)D) and intact parathyroid hormone (s-iPTH). The mean maternal s-25(OH)D was $25 \cdot 8 \mathrm{nmol} / 1$, with $57 \%$ below $25 \mathrm{nmol} / \mathrm{l}$ and $15 \%$ below $12.5 \mathrm{nmol} / 1$. Of the mothers, $26 \%$ had s-iPTH $>5.7 \mathrm{pmol} / \mathrm{l}$. For infants, mean s- $25(\mathrm{OH}) \mathrm{D}$ was $41.7 \mathrm{nmol} / \mathrm{l}$, with $47 \%$ below $25 \mathrm{nmol} / 1$ and $34 \%$ below $12.5 \mathrm{nmol} / \mathrm{l}$. s-25(OH)D was considerably lower in the thirty-one exclusively breast-fed infants (mean $11 \cdot 1 \mathrm{nmol} / \mathrm{l}$; $P<0.0001)$. Use of vitamin D supplements and education showed a positive association with maternal s-25(OH)D. There was no significant association between mother's and child's s-25(OH)D, and no significant ethnic or seasonal variation in s-25(OH)D for mothers or infants. In conclusion, there is widespread vitamin D deficiency in immigrant mothers and their infants living in Norway. Exclusively breast-fed infants who did not receive vitamin D supplements had particularly severe vitamin D deficiency.

Vitamin D: Maternal nutrition: Infant nutrition

Vitamin D is a fat-soluble substance that after activation becomes a hormone with several effects, both on gene transcription and non-genomic effects ${ }^{(1,2)}$. The classical outcomes of severe vitamin D deficiency are rickets and osteomalacia ${ }^{(3)}$. Low vitamin D status has also been related to low bone density and osteoporotic fractures ${ }^{(4)}$. During the last few decades new actions of vitamin $\mathrm{D}$ have been described, and vitamin D deficiency has been proposed as a contributing factor in the development of a variety of other conditions such as tuberculosis, osteoarthritis, multiple sclerosis, diabetes mellitus and some types of cancer ${ }^{(5-9)}$. Vitamin D is synthesised in the skin upon exposure to sunlight (during the summer half of the year in temperate climates) and may also be obtained from a limited number of dietary sources such as fatty fish (mackerel, salmon, trout and herring) and fortified food. Margarine and butter in Norway are fortified with $8 \mu \mathrm{g}$ vitamin $\mathrm{D} / 100 \mathrm{~g}$ and semi-skimmed milk is fortified with $0.4 \mu \mathrm{g}$ vitamin D/100 g. 25-Hydroxyvitamin $\mathrm{D}$ is the main circulating metabolite of vitamin $\mathrm{D}$, and its concentration in serum $(\mathrm{s}-25(\mathrm{OH}) \mathrm{D})$ reflects the vitamin $\mathrm{D}$ stores in humans ${ }^{(9)}$.

In recent years, many immigrants from developing countries have taken up residence in Europe, including Norway. About $6 \%$ of the total Norwegian population of 4.6 million currently consist of non-Western immigrants, and a large proportion of the non-Western immigrant population live in the capital city (Oslo) and surrounding areas. In 2004, 26286 immigrants with Pakistani background and 12971 and 15586 with Turkish and Somali background, respectively, were living in Norway according to Statistics Norway ${ }^{(10)}$, and the proportion among newborns is higher because these groups tend to have more children than do ethnic Norwegians. When individuals migrate from developing countries with prevalent vitamin D deficiency ${ }^{(11,12)}$ to countries at northern latitude such as Norway where UVB radiation is diminished for many months of the year, their vitamin D status will probably worsen unless vitamin D intake is improved. Recent studies have reported a high prevalence of serious vitamin $\mathrm{D}$ deficiency $(\mathrm{s}-25(\mathrm{OH}) \mathrm{D}$ below $12.5 \mathrm{nmol} / \mathrm{l})$ among immigrant adults in Norway ${ }^{(13-15)}$. In one study, a quarter of Pakistani immigrant women aged 30 years had severe vitamin D deficiency defined as secondary hyperparathyroidism $^{(14)}$. The infants of these mothers are at risk of vitamin D deficiency ${ }^{(16)}$. Recent data on rickets collected from paediatric hospitals around Norway shows that nutritional rickets has re-emerged in Norway, particularly in children of Pakistani and Turkish descent ${ }^{(17)}$, but data on vitamin D status among infants with immigrant background in Norway are to our knowledge currently not available. 
The aim of the present study was to describe the distribution of s-25(OH)D among infants aged 6 weeks and their mothers with Pakistani, Turkish and Somali background in Norway, and to investigate the factors associated with vitamin D status among these groups, including the relationship between s-25(OH)D in mother and child.

\section{Material and methods}

\section{Study design and participants}

Participants were recruited at eight child health clinics in Oslo and one in Drammen, a city nearby Oslo, between March 2004 and February 2006. These were selected because they had the highest proportion of immigrants from nonWestern countries. The public health nurses at the child health clinics were requested to ask all mothers with Pakistani, Turkish or Somali background who came for the routine 6-week check-up for their infants if they were willing to participate in the study, involving a blood sample from the mother and child and collection of questionnaire information. Infants were included in the study unless they had a serious disease or condition such as a congenital malformation, which precluded participation in the study, as judged by the public health nurses. Mothers were informed that the study involved an intervention with free vitamin $\mathrm{D}$ drops to the infants and information to the mother aimed at improving the vitamin D status, or usual care, with randomisation at the level of child health clinic. The present paper reports the baseline data for the study, while the results of the intervention are presented elsewhere ${ }^{(18)}$. Those who were willing to participate signed a consent letter and were included in the study. Of the twenty-five child health clinics in Oslo we selected twelve of the child health clinics, where over $85 \%$ of the individuals with immigrant origins live, and eight clinics agreed to participant in recruitment of participants. We have also included one child health clinic in Drammen, just outside of Oslo where more than $80 \%$ of the attending mothers are non-Western immigrants. A total of 119 mothers and their infants affiliated to these eight child health clinics in Oslo and twenty-one mothers in Drammen were asked to participate in the study and a total of eighty-six mothers (sixty-five from Oslo) gave their consent of participation.

\section{Ethical issues}

The study was recommended by the Regional Committees for Medical Research Ethics (reference number S-03 196) and approved by the Norwegian Board of Health and Data Inspectorate.

\section{Blood sampling}

Casual blood samples were collected by public health nurses in the period March 2004 to February 2006. Blood samples were drawn either capillary or venous (optional) from the mothers and capillary from the infants. The amount of capillary blood taken was about $400-600 \mu l$. The public health nurses were trained in blood sampling from infants by the project coordinator, including the use of a standard instruction manual. The blood samples were centrifuged $\left(10 \mathrm{~min} ; 2000 \mathrm{~g}\right.$ at $\left.10^{\circ} \mathrm{C}\right)$ within $30 \mathrm{~min}$ after blood collection and were immediately frozen at $-70^{\circ} \mathrm{C}$ until analysed. $\mathrm{s}-25(\mathrm{OH}) \mathrm{D}_{2}$ and $\mathrm{D}_{3}$ were determined by HPLC-UV-MS (HPLC atmospheric pressure chemical ionisation $\mathrm{MS}$ ) at a commercial laboratory in Oslo ${ }^{(19)}$. s-25(OH)D was expressed as the sum of $\mathrm{D}_{2}$ and $\mathrm{D}_{3}$. A calibration curve was made from analysis of albumin solution enriched with known vitamin D concentrations. Recovery was $>95 \%$, the method is linear from $5-400 \mathrm{nmol} / \mathrm{l}$ at least, and the limit of detection was $1-4 \mathrm{nmol} / \mathrm{l}$. The interassay $\mathrm{CV}$ for vitamin $\mathrm{D}_{3}$ was $7.6 \%$ at a concentration of $47.8 \mathrm{nmol} / \mathrm{l}$ and $6.92 \%$ at a concentration of $83.0 \mathrm{nmol} / \mathrm{l}$. The intra-assay $\mathrm{CV}$ was $7.2 \%$ at a concentration of $47.8 \mathrm{nmol} / \mathrm{l}$ and $6.45 \%$ at a concentration of $83.0 \mathrm{nmol} / 1$. The laboratory is part of the Vitamin D Quality Assessment Scheme.

Serum concentration of intact parathyroid hormone (s-iPTH) was analysed at the Hormone Laboratory, Aker University Hospital, using a non-competitive immunoluminometric assay (Immulite 2500 Diagnostic Products Corporation, Los Angeles, CA, USA). The intra- and inter-assay CV for iPTH were 4 and $9 \%$, respectively. iPTH was only analysed in venous blood samples as there was not sufficient serum from capillary blood samples as this analysis requires $0.5 \mathrm{ml}$ serum. A common universal normal range for s-25(OH)D does not exist; however, we have chosen to use the commonly used cut-off points where vitamin D deficiency is defined as s-25(OH)D below $25 \mathrm{nmol} / 1$ and severe vitamin $\mathrm{D}$ deficiency as $\mathrm{s}-25(\mathrm{OH}) \mathrm{D}$ less than $12.5 \mathrm{nmol} / \mathrm{l}^{(20,21)}$. Hyperparathyroidism was defined as s-iPTH concentration above $5.7 \mathrm{pmol} / \mathrm{l}$, which is the reference limit for the assay in the Hormone Laboratory, Aker University Hospital.

\section{Collection of additional information}

Background information about the infants and their mothers including anthropometry, infant feeding practices and the use of cod liver oil ( $5 \mathrm{ml}$ cod liver oil contains $10 \mu \mathrm{g}$ vitamin D) and other vitamin/mineral supplements (one multivitamin tablet typically contains $5 \mu \mathrm{g}$ vitamin D), years of education and number of years living in Norway, sun exposure and use of food containing vitamin $\mathrm{D}$ was collected by the public health nurses using a structured questionnaire. Foodfrequency questions included have previously been validated and used in the Norwegian Infant Feeding Survey ${ }^{(22)}$. The questionnaire was also piloted among Turkish and Pakistani mothers. Generally, the public health nurses knew the mothers and were confident to undertake the interview without using interpreters.

\section{Statistical methods}

Statistical analysis of the data was performed using the SPSS statistical software (version 11.0; SPSS Inc., Chicago, IL, USA). The relationships between s-25(OH)D and potentially associated variables were tested primarily using linear regression models, both for continuous and categorical explanatory variables. Assumptions of the regression analysis (linearity and similar variance over different levels of the dependent variable) were checked by inspecting plots of residuals against predicted values. Influential points in the regression models were assessed by plotting $\Delta-\beta$ (for each $\beta$-estimate) $v$. observation number to look for data points with strong 
influence $^{(23)}$. Following simple linear regression analyses, we fitted multiple linear regression models for each variable while simultaneously including the explanatory variables that were significant in the simple regression models. Categorisations and measurement scales for the explanatory variables are specified in the Results section (Tables 2 and 4). Wherever we found evidence of violation of the assumptions of the linear regression analysis, we used non-parametric tests (Kruskal-Wallis and Mann-Whitney tests and Spearman correlation) as specified together with the results. $P$ values below 0.05 were considered statistically significant.

\section{Results}

A total of eighty-six mothers and their infants were included, but serum was not available from six of these mothers because they declined to give the blood sample. Characteristics of the study population are shown in Table 1 . The mothers had been living in Norway for an average of more than 10 years. One in three mothers reported eating fatty fish at least twice per week whereas one in four stated that they took vitamin D supplements daily (mean vitamin D intake from supplements was $7.6(\mathrm{SD} 3.8) \mu \mathrm{g} / \mathrm{d})$. Most of the mothers reported that they still used traditional dress while outdoors and about half of all mothers covered their whole body including legs, hands and face while outside their houses.

\section{Mothers}

The mean concentration of s-25(OH)D was $25 \cdot 8$ (SD 15.2) $\mathrm{nmol} / \mathrm{l}$ for mothers (Table 1$) ; 57 \%$ had s-25(OH)D $<25$ $\mathrm{nmol} / \mathrm{l}$, while $15 \%$ had $\mathrm{s}-25(\mathrm{OH}) \mathrm{D}<12.5 \mathrm{nmol} / \mathrm{l}$. Seven

Table 1. Characteristics of the study population

(Numbers and percentages or mean values and standard deviations)

\begin{tabular}{|c|c|c|c|c|c|c|c|c|c|}
\hline & \multicolumn{2}{|c|}{ Pakistani } & \multicolumn{2}{|c|}{ Turkish } & \multicolumn{2}{|c|}{ Somali } & \multicolumn{3}{|c|}{ All } \\
\hline & $n$ & $\%$ & $n$ & $\%$ & $n$ & $\%$ & $n$ & & $\%$ \\
\hline Mothers $(n)$ & 45 & & 25 & & 10 & & 80 & & \\
\hline \multicolumn{10}{|l|}{ Age (years) } \\
\hline Mean & \multicolumn{2}{|c|}{$28 \cdot 4$} & \multicolumn{2}{|c|}{$26 \cdot 8$} & \multicolumn{2}{|c|}{$30 \cdot 4$} & \multicolumn{3}{|c|}{$28 \cdot 1$} \\
\hline $\mathrm{SD}$ & \multicolumn{2}{|c|}{4.9} & \multicolumn{2}{|c|}{$5 \cdot 7$} & \multicolumn{2}{|c|}{4.6} & \multicolumn{3}{|c|}{$5 \cdot 2$} \\
\hline \multicolumn{10}{|l|}{ BMI $\left(\mathrm{kg} / \mathrm{m}^{2}\right)$} \\
\hline Mean & \multirow{2}{*}{\multicolumn{2}{|c|}{$\begin{array}{r}26.9 \\
4.7\end{array}$}} & \multirow{2}{*}{\multicolumn{2}{|c|}{$\begin{array}{r}27 \cdot 2 \\
4 \cdot 2\end{array}$}} & \multirow{2}{*}{\multicolumn{2}{|c|}{$\begin{array}{r}26 \cdot 6 \\
3 \cdot 8\end{array}$}} & \multirow{2}{*}{\multicolumn{3}{|c|}{$\begin{array}{r}27.0 \\
4.4\end{array}$}} \\
\hline SD & & & & & & & & & \\
\hline Education $<10$ years & 38 & 17 & 56 & 14 & 70 & 7 & 48 & & 38 \\
\hline \multicolumn{10}{|l|}{ Time lived in Norway (years) } \\
\hline Mean & \multirow{2}{*}{\multicolumn{2}{|c|}{$\begin{array}{r}10.9 \\
8.1\end{array}$}} & \multirow{2}{*}{\multicolumn{2}{|c|}{$\begin{array}{r}12 \cdot 2 \\
0 \cdot 9\end{array}$}} & \multicolumn{2}{|c|}{$7 \cdot 8$} & \multicolumn{3}{|c|}{$10 \cdot 9$} \\
\hline SD & & & & & & & & 8.0 & \\
\hline Taking vitamin D supplements daily & 29 & 13 & 16 & 4 & 40 & 4 & 26 & & 21 \\
\hline Fatty fish intake $\geq$ twice per week & 36 & 16 & 24 & 6 & 70 & 7 & 36 & & 29 \\
\hline Using fortified butter or margarine daily & 73 & 33 & 76 & 19 & 70 & 7 & 74 & & 59 \\
\hline Using fortified milk daily & 11 & 5 & 8 & 2 & 0 & & 9 & & 7 \\
\hline Time spent outside in summer season $>1 \mathrm{~h}$ & 51 & 23 & 72 & 18 & 70 & 7 & 60 & & 48 \\
\hline Mostly covered† & 44 & 20 & 44 & 11 & 80 & 8 & 49 & & 39 \\
\hline $\mathrm{s}-25(\mathrm{OH}) \mathrm{D}(\mathrm{nmol} / \mathrm{l})$ & & & & & & & & & \\
\hline Mean & & & & & & & & $25 \cdot 8$ & \\
\hline SD & & & & & & & & $15 \cdot 2$ & \\
\hline $\mathrm{s}-25(\mathrm{OH}) \mathrm{D}(\%)$ & & & & & & & & & \\
\hline$<12.5 \mathrm{nmol} / \mathrm{l}$ & & 18 & & 12 & & 10 & & & 15 \\
\hline $12.5-24.9 \mathrm{nmol} / \mathrm{l}$ & & 33 & & 44 & & 80 & & & 42 \\
\hline $25-49.9 \mathrm{nmol} / \mathrm{l}$ & & 42 & & 32 & & 0 & & & 34 \\
\hline$\geq 50 \mathrm{nmol} / \mathrm{l}$ & & 7 & & 12 & & 10 & & & 9 \\
\hline Serum iPTH (pmol//)‡ & & & & & & & & & \\
\hline Mean & & & & & & & & $6 \cdot 1$ & \\
\hline SD & & & & & & & & 3.7 & \\
\hline Infants $(n)$ & 50 & & 25 & & 11 & & 86 & & \\
\hline Age (weeks) & & & & & & & & & \\
\hline Mean & & & & & & & & $6 \cdot 8$ & \\
\hline SD & & & & & & & & 1.6 & \\
\hline Taking vitamin D supplements daily & 36 & 18 & 27 & 7 & 54 & 6 & 36 & & 31 \\
\hline $\mathrm{s}-25(\mathrm{OH}) \mathrm{D}(\mathrm{nmol} / \mathrm{l})$ & & & & & & & & & \\
\hline Mean & & & & & & & & $41 \cdot 7^{\star}$ & \\
\hline SD & & & & & & & & 35.7 & \\
\hline s-25(OH)D (\%) & & & & & & & & & \\
\hline$<12.5 \mathrm{nmol} / \mathrm{l}$ & & 34 & & 48 & & 0 & & & 34 \\
\hline $12.5-24.9 \mathrm{nmol} / \mathrm{l}$ & & 18 & & 8 & & 0 & & & 13 \\
\hline $25-49.9 \mathrm{nmol} / \mathrm{l}$ & & 6 & & 8 & & 55 & & & 13 \\
\hline$\geq 50 \mathrm{nmol} / \mathrm{l}$ & & 42 & & 36 & & 45 & & & 40 \\
\hline
\end{tabular}

s-25(OH)D, serum hydroxyvitamin D; iPTH, intact parathyroid hormone.

${ }^{*} P=0.49$. Because of unequal variances we used a non-parametric test (Kruskal-Wallis; $P=0.28$ ).

†Cover head, hands and legs with clothes.

$\ddagger$ Pakistani ( $n$ 25), Turkish ( $n$ 15), Somali $(n 7)$. 
mothers $(9 \%)$ had s-25(OH)D concentrations over $50 \mathrm{nmol} / \mathrm{l}$. The mean concentrations of s-25(OH)D were $26 \cdot 1$ (SD 16.4) $\mathrm{nmol} / \mathrm{l}$ for mothers sampled in April-September $(n 40)$ and 25.7 (SD 14.3) nmol/l for mothers sampled in OctoberMarch ( $n$ 46) $(P=0.91)$. There was no significant ethnic variation in maternal s-25(OH)D levels.

s-iPTH concentrations were available for forty-seven of the mothers (those with venous blood samples). The mean concentration of s-iPTH was 6.1 (SD 3.7) pmol/l; $45 \%$ of the mothers had elevated s-iPTH $(>5.7 \mathrm{pmol} / \mathrm{l})$. There was a significant negative correlation between s-25(OH)D and s-iPTH for the mothers (Spearman correlation, $r-0 \cdot 30, P=0 \cdot 04$; Fig. 1). Although we had limited power to study the precise shape of this association, a clear upturn in s-iPTH was suggested to start at s-25(OH)D levels of about 20$30 \mathrm{nmol} / \mathrm{l}$. There was no seasonal variation in s-iPTH levels.

Mothers who used vitamin D-containing supplements daily and those with longer education had significantly higher s-25(OH)D than other mothers, while other variables such as intake of fatty fish, use of fortified foods, sun exposure, clothing habits and season were not associated with s-25(OH)D (Table 2). Among the supplemented group, $76 \%$ of the mothers with more than 10 years of education and $24 \%$ of those with lower education level were taking vitamin D supplements daily.

\section{Infants}

The mean concentrations of s-25(OH)D were $43 \cdot 3$ (SD 30.5) and 40.9 (SD 39.9) $\mathrm{nmol} / \mathrm{l}$ for infants sampled in AprilSeptember and October-March, respectively, and did not significantly vary with the season of the year the blood sample was collected $(P=0 \cdot 70)$.

The mean concentration of $\mathrm{s}-25(\mathrm{OH}) \mathrm{D}$ was $41.7 \mathrm{nmol} / 1$ for all infants (Table 1). Half of the Turkish and one-third of the Pakistani infants had s-25(OH)D $<12.5 \mathrm{nmol} / 1$ whereas all of the Somali infants had levels above $25 \mathrm{nmol} / \mathrm{l}$. Around $60 \%$ of all infants had s-25(OH)D concentrations below $50 \mathrm{nmol} / \mathrm{l}$. The s-25(OH)D concentrations were not significantly different between the three ethnic groups.

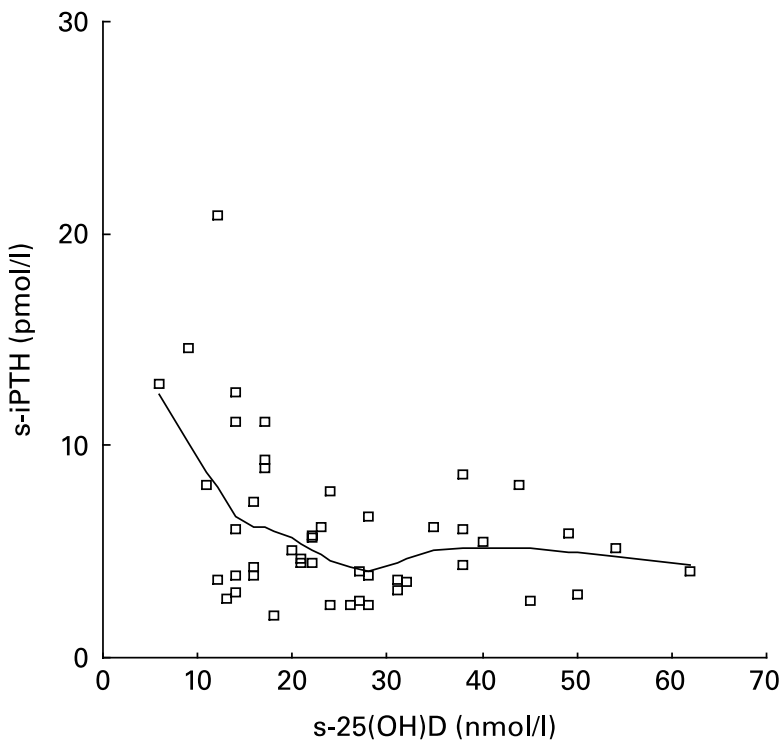

Fig. 1. Association (Spearman correlation; $r-0.30, P=0.04$ ) between serum 25-hydroxyvitamin $D(\mathrm{~s}-25(\mathrm{OH}) \mathrm{D})$ and serum intact parathyroid hormone (s-iPTH) concentrations in mothers of immigrant origin residing in Norway ( $n$ 47). The line was fitted using LOWESS smoother in SPSS version 11.0 (SPSS Inc., Chicago, IL, USA).

s-25(OH)D was significantly associated with infant feeding practices (Table 3). Of all the infants, about $55 \%$ were fully breast-fed; among these about $67 \%$ were exclusively breast-fed and the remaining $33 \%$ were reported to take vitamin D supplements daily (as cod liver oil). The s-25(OH)D concentrations were higher among fully breastfed infants with vitamin D supplements compared with the exclusively breast-fed infants $(P=0 \cdot 001)$.

Among the thirty-one exclusively breast-fed infants, the mean s-25(OH)D was $11 \cdot 1 \mathrm{nmol} / 1$ and $71 \%(n 22)$ of them had s-25(OH)D $<12.5 \mathrm{nmol} / \mathrm{l}$. Infants receiving infant formula had the highest s-25(OH)D and about $85 \%$ of those infants who received infant formula $(100 \mathrm{ml}$ infant formula contains $1 \mu \mathrm{g}$ vitamin $\mathrm{D}_{3}$ ) started under the age of 4 weeks.

Table 2. Relationship between serum 25-hydroxyvitamin $D(\mathrm{nmol} / \mathrm{l})$ and potentially associated factors in mothers of immigrant origin residing in Norway $(n 79)^{*}$

(B estimates and $95 \%$ confidence intervals)

\begin{tabular}{|c|c|c|c|c|c|c|}
\hline Explanatory variables & Unadjusted B estimate & $95 \% \mathrm{Cl}$ & $P$ & Adjusted B estimate $†$ & $95 \% \mathrm{Cl}$ & $P$ \\
\hline Vitamin D supplementł & $8 \cdot 9$ & $2 \cdot 4,15 \cdot 4$ & 0.008 & $6 \cdot 5$ & $0.5,13.0$ & 0.05 \\
\hline Education§ & $9 \cdot 1$ & $3 \cdot 5,15 \cdot 4$ & 0.002 & $7 \cdot 5$ & $1 \cdot 7,13 \cdot 3$ & 0.01 \\
\hline Sun exposure\|l & -0.99 & $-9 \cdot 2,9 \cdot 3$ & 0.8 & -0.5 & $-8 \cdot 1,7 \cdot 1$ & 0.7 \\
\hline Veiled & $-4 \cdot 3$ & $-10 \cdot 3,1 \cdot 6$ & $0 \cdot 2$ & -2.5 & $-8 \cdot 3,3 \cdot 3$ & 0.4 \\
\hline Fish intake & $1 \cdot 2$ & $-5 \cdot 0,7 \cdot 5$ & 0.7 & 0.3 & $5 \cdot 7,6 \cdot 4$ & 0.9 \\
\hline Butter or margarine†† & $5 \cdot 6$ & $-1 \cdot 0,12 \cdot 3$ & $0 \cdot 1$ & 4.9 & $-1 \cdot 3,11 \cdot 2$ & $0 \cdot 1$ \\
\hline Season blood takenł‡ & $1 \cdot 3$ & $-4 \cdot 7,7 \cdot 3$ & 0.7 & -0.1 & $-5 \cdot 8,5 \cdot 6$ & 0.9 \\
\hline
\end{tabular}

* The $\Delta-\beta$ plots to assess influential points showed one subject with high influence in the regression and this subject was excluded from the analysis. With this subject included, the unadjusted B estimates for vitamin D supplements and education were $7.7(95 \% \mathrm{Cl} 0.13,15.3)$ and $7.3(95 \% \mathrm{Cl} 0.7,13.9)$, respectively, and the adjusted $\mathrm{B}$ estimates for vitamin $\mathrm{D}$ supplements and education were $5.8(95 \% \mathrm{Cl}-1.9,13.6)$ and $5.8(95 \% \mathrm{Cl}-1 \cdot 0,12 \cdot 7)$, respectively.

$\dagger$ Adjusted for variables that are significant in simple linear regression (vitamin D supplements and education).

$\ddagger$ Use of vitamin $D$ supplements (coded as $0=$ no, 1 = yes).

§Education level (coded as $1, \leq 10$ years; $2,>10$ years)

\| Time spent outside (coded as $1, \leq 0.5 \mathrm{~h} ; 2$, above $0.5 \mathrm{~h}$ ).

I Cover head, hands and legs (coded as $0=$ no, $1=$ yes).

${ }^{\star *}$ Fatty fish intake (coded as $1,<$ two times/week; $2, \geq$ two times/week).

††Use of butter or margarine for spreads or cooking daily $(0=$ no, $1=$ yes $)$

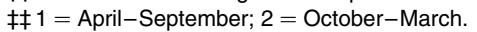


Table 3. Breast-feeding practices, use of infant formula and serum 25-hydroxyvitamin $\mathrm{D}(\mathrm{s}-25(\mathrm{OH}) \mathrm{D})$ in infants aged 6 weeks of immigrant origin residing in Norway

(Mean values and standard deviations)

\begin{tabular}{|c|c|c|c|}
\hline & \multirow[b]{2}{*}{ Subjects $(n)$} & \multicolumn{2}{|c|}{$\mathrm{s}-25(\mathrm{OH}) \mathrm{D}$ level $(\mathrm{nmol} / \mathrm{l})$} \\
\hline & & Mean & SD \\
\hline All infants & 86 & $41 \cdot 7$ & $35 \cdot 7$ \\
\hline $\begin{array}{l}\text { Exclusively breast-fed } \\
\text { (no supplements) }\end{array}$ & 31 & $11 \cdot 1^{*}$ & $13 \cdot 7$ \\
\hline $\begin{array}{l}\text { Breast-feeding plus } \\
\text { vitamin D supplements }\end{array}$ & 15 & 33.5 & $29 \cdot 7$ \\
\hline Partially breast-fed† & 33 & 64.5 & 25.5 \\
\hline Only infant formula & 7 & $90 \cdot 7$ & $27 \cdot 9$ \\
\hline
\end{tabular}

* Mean value was significantly different from that of the breast-fed infants with vitamin D supplements $(P<0.0001$; linear regression analysis).

† Breast milk plus infant formula.

There was no significant relationship between mother's and infant's s-25(OH)D (Table 4). This was also the case when restricting the analysis to exclusively breast-fed infants. Neither was s-25(OH)D concentrations of the infants related to other potentially relevant maternal factors.

\section{Discussion}

In the present study we found that immigrant mothers of Pakistani, Turkish and Somali origin and their infants born in Norway had poor vitamin D status, particularly the exclusively breast-fed infants, which is consistent with other studies ${ }^{(13-15,24-26)}$. Elevated s-iPTH was also common among mothers, and there was an inverse association between s-25(OH)D and s-iPTH, which is also in line with a similar study among Pakistani immigrants in Denmark ${ }^{(24)}$.

\section{Factors associated with maternal vitamin D status}

Daily use of vitamin D supplements was positively associated with vitamin D status of the mothers. In Norway only margarine, butter and one type of milk (extra semi-skimmed milk) are fortified with vitamin D and although $74 \%$ of the mothers reported a daily use of fortified butter and margarine for cooking and bread spreads we were not able to detect any association between intake of these foods and vitamin D status. Fatty fish is an important source of vitamin D in the Norwegian diet. However, the one-third of the mothers reported eating such fish at least twice per week did not have higher levels of s-25(OH)D than the rest. This is in contrast to the positive effect of fish consumption on s-25(OH)D which has previously been observed in immigrants in Norway and the Netherlands ${ }^{(13,27)}$. The lack of associations between the factors such as consumption of fatty fish and fortified food and vitamin D status shows that even if we used carefully selected questions, these questions did not provide reliable information on vitamin intake in these immigrant mothers as they were not related to s-25(OH)D levels which is a valid indicator of vitamin $\mathrm{D}$ status.

We found that the education level of the mothers influenced $\mathrm{s}-25(\mathrm{OH}) \mathrm{D}$, partly because the mothers with higher education reported taking vitamin $\mathrm{D}$ supplements to a higher degree than the least educated mothers. Educational level may be a marker of the acquirement of a Western lifestyle. This trend has also been seen in another study among immigrants in Norway ${ }^{(13)}$. Other factors such as BMI, clothes wearing habits and time spent outdoors during summer did not influence the s-25(OH)D concentrations of the mothers. Although the majority of the women reported that they spent time outdoors during summer, seasonal variation in s-25(OH)D was not observed. This may be because a substantial proportion of the mothers maintained their wearing habits (hijab), which means that they covered their head, arms and legs, limiting direct sun exposure to the skin. Similar results were observed in veiled women in the Middle East and Turkey ${ }^{(28-30)}$.

\section{Infant vitamin D status}

In Norway exclusive breast-feeding for at least 6 months and vitamin D supplementation from the age of 4 weeks is recommended, but the present results indicate that these official recommendations are not followed by all mothers.

Table 4. Serum 25-hydroxyvitamin D (s-25(OH)D) levels in all infants and exclusively breast-fed infants stratified by maternal s-25(OH)D and background parameters*

(B estimates and $95 \%$ confidence intervals)

\begin{tabular}{|c|c|c|c|c|c|c|}
\hline & \multicolumn{3}{|c|}{ All infants $(n 86)$} & \multicolumn{3}{|c|}{ Exclusively breast-fed infants ( $n 31)$} \\
\hline & Unadjusted B estimate & $95 \% \mathrm{Cl}$ & $P$ & Unadjusted B estimate & $95 \% \mathrm{Cl}$ & $P$ \\
\hline Maternal s-25(OH)D levels (nmol/l) & -0.26 & $-0.8,0.3$ & 0.3 & -0.08 & $-0.46,0.30$ & 0.7 \\
\hline Maternal s-iPTH $\dagger$ & -0.40 & $-3 \cdot 3,2 \cdot 5$ & 0.8 & -1.0 & $-2 \cdot 4,0.36$ & $0 \cdot 1$ \\
\hline Maternal education $\ddagger$ & $-2 \cdot 2$ & $-18 \cdot 5,14 \cdot 1$ & 0.8 & $-10 \cdot 5$ & - & $0.15 \S$ \\
\hline Maternal use of vitamin D supplements daily\|l & $-4 \cdot 6$ & $-23 \cdot 1,13 \cdot 8$ & 0.6 & 5.9 & $-5 \cdot 1,17 \cdot 0$ & 0.3 \\
\hline
\end{tabular}

s-iPTH, serum intact parathyroid hormone.

* Linear regression analysis.

† Hyperparathyroidism was defined as s-iPTH concentration above $5.7 \mathrm{pmol} / \mathrm{l}$.

$\ddagger$ Education level (coded as $1, \leq 10$ years; $2,>10$ years).

$\S$ There were evidence for unequal variances between the groups, so the assumption of linear regression was violated. The $P$ value is based on the non-parametric Mann-Whitney test. The s-25(OH)D concentration of exclusively breast-fed infants with mothers of lower education was 16.5 (SD 10.4 ) nmol/l and for those whose mothers had higher education it was $6 \cdot 1$ (SD 3.6) nmol/l.

|| Use of vitamin D supplements daily (coded as $0=$ no, $1=$ yes). 
While over $87 \%$ of ethnic Norwegian infants are exclusively breast-fed at the age of $6-8$ weeks ${ }^{(22)}$, only $36 \%$ of the infants of Pakistani, Turkish and Somali immigrant mothers in the present study were exclusively breast-fed at the age of 6 weeks. It is well documented that breast-fed infants without vitamin D supplements or sun exposure are at great risk for vitamin D deficiency, because human milk is a poor source of vitamin $\mathrm{D}^{(31)}$. During the first weeks of life, the vitamin D status of infants is dependent on their vitamin D stores at birth unless they are given vitamin D supplements or exposed to sunlight. Some studies have found that exclusively breast-fed infants' vitamin D status correlate with those of their mothers within the first weeks of life ${ }^{(11,12)}$. We found that at about 6 weeks after birth there was no relationship between the mothers' and infants' vitamin D status, suggesting that the relationship between mothers' and infants' vitamin D status vanishes during the first 6-7 weeks after birth. The number of exclusively breast-fed infants was small which might limit the study's power to detect any correlation between infant and maternal vitamin $D$ status. However, a longitudinal measurement of s-25(OH)D of exclusively breast-fed infants born to mothers with normal vitamin D status found that a depletion of vitamin D stores of infants occurs within 8 weeks after delivery ${ }^{(32)}$. There was a $36 \%$ of the infants who received vitamin $\mathrm{D}$ supplements, and these infants had significantly higher s-25(OH)D than exclusively breast-fed infants. We have recently also shown that providing vitamin D drops to immigrant infants has a significantly positive effect on their vitamin D status ${ }^{(18)}$.

\section{Limitations}

The recruitment of study subjects was undertaken by local public health nurses, who did this in addition to their daily routine assignments. It is possible that the public health nurses did not register all the mothers who were eligible for the study but declined to participate, and most probably some were not asked to participate, which both might lead to selection bias. However, comparison of the education levels of included mothers to data from Statistics Norway ${ }^{(10)}$ suggests that the mothers included in the present study are representative of mothers with Pakistani, Turkish and Somali background living in Norway. Five of the six mothers who rejected to take blood tests were Pakistanis and had the same characteristics as the study population. Another limitation could be the questionnaire. The public health nurses filled in the questionnaires while asking questions to mothers, and poor Norwegian knowledge of mothers and limited time of the public health nurses might have influenced the communications. For instance, those with limited Norwegian knowledge may have not understood all the questions, especially questions on sun exposure, duration of sun exposure, fatty fish and consumption of fortified food. The other issue of concern is the relationship between public health nurses and the mothers which might have influenced the responses of the mothers. S-iPTH values could not be determined in all mothers because of insufficient serum volume in the thirty-three mothers with capillary blood samples, but we found no difference in s-25(OH)D concentrations between the mothers whose s-iPTH was measured and other mothers (data not shown).

\section{Conclusions}

We report that, regardless of season, exclusively breast-fed infants who did not receive vitamin D supplements had severe vitamin $\mathrm{D}$ deficiency. On average the mothers also had very low vitamin $\mathrm{D}$ status. In addition, there was no relationship between vitamin $D$ status in the infants and their mothers. We found that the most important factor for vitamin $\mathrm{D}$ status in the mothers was vitamin $\mathrm{D}$ supplements. The health impact of these low s-25(OH)D concentrations on different ethnic groups should be further investigated.

\section{Acknowledgements}

We thank all mothers, public health nurses and members of the study advisory group Leif Brunvand, Aud Haugen, ElseKarin Grøholt and Kirsten Berge, our child health clinics coordinator, for their help with the study. H. E. M. and A. A. M. planned the study. A. A. M. carried out the data collection, performed data analysis and prepared the manuscript. H. E. M. and L. C. S. commented on the draft, contributed to the interpretation of the findings and approved the final version of the manuscript. The study was funded by the Directorate for Health and Social Affairs. The authors declare no conflict of interest with regard to this paper.

\section{References}

1. Holick MF (2003) Evolution and function of vitamin D. Recent Results Cancer Res 164, 3-28.

2. Holick MF (2006) Vitamin D. In Modern Nutrition in Health and Disease, 10th ed., pp. 376-395 [ME Shils, M Shike, AC Ross, B Caballero and RJ Cousins, editors]. Hagerstown, MD: Lippincott Williams \& Wilkins.

3. Heaney RP (2003) Long-latency deficiency disease: insights from calcium and vitamin D. Am J Clin Nutr 78, 912-919.

4. Lips P (2001) Vitamin D deficiency and secondary hyperparathyroidism in the elderly: consequences for bone loss and fractures and therapeutic implications. Endocr Rev 22, 477-501.

5. Chan TY (2000) Vitamin D deficiency and susceptibility to tuberculosis. Calcif Tissue Int 66, 476-478.

6. Sowers M \& Lachance L (1999) Vitamins and arthritis. The roles of vitamins A, C, D, and E. Rheum Dis Clin North Am 25, 315-332.

7. VanAmerongen BM, Dijkstra CD, Lips P \& Polman CH (2004) Multiple sclerosis and vitamin D: an update. Eur J Clin Nutr 58, 1095-1109.

8. Jacobs ET, Giuliano AR, Martinez EM, Hollis BW, Reid ME \& Marshall JR (2004) Plasma levels of 25-hydroxyvitamin D. 1,25-dihydroxyvitamin $\mathrm{D}$ and the risk of prostate cancer. J Steroid Biochem Mol Biol 89-90, 533-537.

9. Holick MF (2003) Vitamin D: a millenium perspective. J Cell Biochem 88, 296-307.

10. Statistics Norway (2007) SA 87: Immigration and Immigrants 2006. http://www.ssb.no/english/subjects/02/sa_innvand_en/sa87 (accessed May 2008).

11. Atiq M, Suria A, Nizami SQ \& Ahmed I (1998) Maternal vitamin-D deficiency in Pakistan. Acta Obstet Gynecol Scand 77, 970-973.

12. Andiran N, Yordam N \& Ozon A (2002) Risk factors for vitamin $\mathrm{D}$ deficiency in breast-fed newborns and their mothers. Nutrition 18, 47-50. 
13. Holvik K, Meyer HE, Haug E \& Brunvand L (2005) Prevalence and predictors of vitamin $\mathrm{D}$ deficiency in five immigrant groups living in Oslo, Norway: the Oslo Immigrant Health Study. Eur J Clin Nutr 59, 57-63.

14. Meyer HE, Falch JA, Sogaard AJ \& Haug E (2004) Vitamin D deficiency and secondary hyperparathyroidism and the association with bone mineral density in persons with Pakistani and Norwegian background living in Oslo, Norway, The Oslo Health Study. Bone 35, 412-417.

15. Henriksen C, Brunvand L, Stoltenberg C, Trygg K, Haug E \& Pedersen JI (1995) Diet and vitamin-D status among pregnant Pakistani women in Oslo. Eur J Clin Nutr 49, 211-218.

16. Ziegler EE, Hollis BW, Nelson SE \& Jeter JM (2006) Vitamin D deficiency in breastfed infants in Iowa. Pediatrics 118, 603-610.

17. National Council for Nutrition (2001) The Norwegian Directorate of Health and Social Services. Report on Measures on how to Prevent Vitamin D Deficiency (In Norwegian). Oslo, Norway: National Council for Nutrition.

18. Madar AA, Klepp KI \& Meyer HE (2008) Effect of free vitamin $\mathrm{D}(2)$ drops on serum 25-hydroxyvitamin D in infants with immigrant origin: a cluster randomized controlled trial. Eur J Clin Nutr, (epublication ahead of print version 30 January 2008).

19. Vitas, Chemical analysis. http://www.vitas.no/chemical analysis_index.shtml (accessed May 2008)2008

20. Greer FR (2004) Issues in establishing vitamin D recommendations for infants and children. Am J Clin Nutr 80, 1759-1762.

21. Lips P (2004) Which circulating level of 25-hydroxyvitamin D is appropriate? J Steroid Biochem Mol Biol 89-90, 611-614.

22. Lande B, Andersen LF, Baerug A, Trygg KU, Lund-Larsen K \& Veierod MB (2003) Infant feeding practices and associated factors in the first six months of life: the Norwegian Infant Nutrition Survey. Acta Paediatrica 92, 152-161.

23. Kleinbaum DG, Kupper L, Muller KE \& Nizam A (1998) Applied Regression Analysis and Multivariable Methods, 3rd ed. Pacific Grove, CA: Duxbury Press.
24. Andersen R, Molgaard C, Skovgaard LT, Brot C, Cashman KD \& Jakobsen J (2008) Pakistani immigrant children and adults in Denmark have severely low vitamin D status. Eur J Clin Nutr 62, 625-634.

25. Van der Meer IM, Karamali NS, Boeke AJP, Lips P, Middelkoop BJC \& Verhoeven (2006) High prevalence of vitamin $\mathrm{D}$ deficiency in pregnant non-Western women in The Hague, Netherlands. Am J Clin Nutr 84, 350-353.

26. Erkal MZ, Wilde J, Bilgin Y, Akinci A, Demir E \& Bodeker RH (2006) High prevalence of vitamin D deficiency, secondary hyperparathyroidism and generalized bone pain in Turkish immigrants in Germany: identification of risk factors. Osteoporos Int 17, 1133-1140.

27. Van der Meer IM, Boeke AJ, Lips P, Grootjans-Geerts I, Wuister JD \& Deville WL (2008) Fatty fish and supplements are the greatest modifiable contributors to the serum 25-hydroxyvitamin D concentration in a multiethnic population. Clin Endocrinol (Oxf) 68, 466-472.

28. Dawodu A, Agarwal M, Hossain M, Kochiyil J \& Zayed R (2003) Hypovitaminosis D and vitamin D deficiency in exclusively breast-feeding infants and their mothers in summer: a justification for vitamin D supplementation of breast-feeding infants. J Pediatr 142, 169-173.

29. Alagol F, Shihadeh Y, Boztepe H, Tanakol R, Yarman S \& Azizlerli H (2000) Sunlight exposure and vitamin D deficiency in Turkish women. J Endocrinol Invest 23, 173-177.

30. Mishal AA (2001) Effects of different dress styles on vitamin D levels in healthy young Jordanian women. Osteoporosis Int 12, 931-935.

31. Hollis BW, Roos BA, Draper HH \& Lambert PW (1981) Vitamin D and its metabolites in human and bovine milk. J Nutr 111, 1240-1248.

32. Hoogenboezem $\mathrm{T}$, Degenhart HJ, Keizerschrama SMPFD, Bouillon R, Grose WFA \& Hackeng WHL (1989) Vitamin-D metabolism in breast-fed infants and their mothers. Pediatr Res 25, 623-628. 